CNS Spectrums (2019), 24, 114-126. (C) Cambridge University Press 2019. This is an Open Access article, distributed under the terms of the Creative Commons Attribution licence (http://creativecommons.org/licenses/by/4.0/), which permits unrestricted reuse, distribution, and reproduction in any medium, provided the original work is properly cited.

\title{
Mental imagery in psychiatry: conceptual \& clinical implications
}

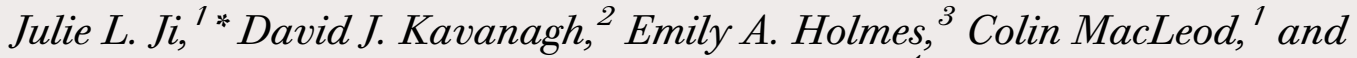 \\ Martina Di Simplicio ${ }^{4}$
}

\footnotetext{
${ }^{1}$ Centre for the Advancement of Research on Emotion, School of Psychological Science, University of Western Australia, Australia

${ }^{2}$ Institute of Health \& Biomedical Innovation and School of Psychology \& Counselling, Queensland University of Technology, Brisbane, Australia

${ }^{3}$ Division of Psychology, Department for Clinical Neuroscience, Karolinska Institutet, Stockholm, Sweden

${ }^{4}$ Centre for Psychiatry, Imperial College London, UK
}

Mental imagery refers to the experience of perception in the absence of external sensory input. Deficits in the ability to generate mental imagery or to distinguish it from actual sensory perception are linked to neurocognitive conditions such as dementia and schizophrenia, respectively. However, the importance of mental imagery to psychiatry extends beyond neurocognitive impairment. Mental imagery has a stronger link to emotion than verbal-linguistic cognition, serving to maintain and amplify emotional states, with downstream impacts on motivation and behavior. As a result, anomalies in the occurrence of emotion-laden mental imagery has transdiagnostic significance for emotion, motivation, and behavioral dysfunction across mental disorders. This review aims to demonstrate the conceptual and clinical significance of mental imagery in psychiatry through examples of mood and anxiety disorders, self-harm and suicidality, and addiction. We contend that focusing on mental imagery assessment in research and clinical practice can increase our understanding of the cognitive basis of psychopathology in mental disorders, with the potential to drive the development of algorithms to aid treatment decision-making and inform transdiagnostic treatment innovation.

Received 19 February 2018; Accepted 4 October 2018; First published online 28 January 2019

Key words: addiction, anxiety disorders, dementia, emotion, mental imagery, motivation, mood disorders, schizophrenia, self-harm.

\section{What is Mental Imagery?}

Our conscious cognition can occur in mental imagery or verbal-linguistic formats. Mental imagery refers to perceptual experiences based on information stored in memory, in the absence of external sensory input, ${ }^{1}$ commonly referred to as seeing in the "mind's eye," hearing in the "mind's ear," etc. ${ }^{1}$ Mental imagery can be multi-sensory and occur in a variety of forms, from fleeting sensory impressions and static scenes (mental pictures) to detailed re-play or pre-play of events situated in a specific space, time, and context (mental movies). Mental imagery is involved in many everyday cognitive functions $^{2}$ such as spatial navigation ${ }^{3}$ and language comprehension. ${ }^{4}$ Mental imagery also plays a special role in representing our past and future experiences ${ }^{5,6}$ that is believed to facilitate adaptive decision-making, planning,

* Address for correspondence: Dr. Julie L. Ji, School of Psychological Science, The University of Western Australia, 35 Stirling Hwy, Crawley 6009 WA Australia. (Email: julie.ji@uwa.edu.au) and self-regulatory behavior. ${ }^{7,8}$ Importantly, the ability for mental imagery to emulate real-life experience ${ }^{9}$ can powerfully impact emotion ${ }^{5,10}$ and motivation. ${ }^{11}$

While mental imagery dysfunction linked to neurocognitive impairment are implicated in mental disorders such as the dementias ${ }^{12}$ and schizophrenia, ${ }^{13}$ anomalies in the occurrence of mental imagery-based representations of salient stimuli is also prevalent across mental disorders and contribute to emotional, motivational, and behavioral dysregulation. Through examples of mood and anxiety disorders, self-harm and suicidality, and addiction, the present review aims to characterize the conceptual and clinical significance of mental imagery-based cognition as a tool for assessing psychopathology, and as a potential treatment target and a source of treatment innovation.

\section{Approaches to Measuring Mental Imagery}

When practitioners ask patients "what was running through your mind?" at times of reported distress, the assumption is that the content of cognition would assist in 
identifying factors that may be contributing to the distress. The present review contends that, in addition to the content of cognition, the representation format of such content (imagery or verbal) holds additional information about the impact of cognition. In other words, inviting patients to report on whether their cognition involved mental imagery may provide additional insight into the nature of psychopathology. ${ }^{14}$ Here, we move away from the standard clinical interview to possible research tools, too, some of which may also be useful in clinical practice.

\section{Reporting naturally occurring mental imagery}

Mental imagery can be consciously experienced and reported to another person, subject to the individual's capacity to translate such experience into words or ratings and their willingness to communicate it. Clinically, people can report on their imagery in an assessment once given a definition of what is meant by mental imagery (eg, for intrusive memories in post-traumatic stress disorder [PTSD]). Retrospective reporting of mental imagery can introduce memory biases. ${ }^{15}$ Thus, it may be desirable to minimize these effects in retrospective reports (eg, focusing on salient imagery or recent imagery rather than usual or average ratings), particularly for research purposes. Momentary assessments are now possible using mobile technologies, which can prompt the recording of naturally occurring cognition. If problematic emotion or behavior are more likely during certain times or occasions, prompts to record imagery can be scheduled accordingly. As such recording still relies on the person's adherence, random sampling or assessment over selected periods may minimize the task burden. Initial tests of the feasibility of such methods are already underway in depression and anxiety research, with promising results. ${ }^{16,17}$

\section{Questionnaire measures of mental imagery}

Standardized measures of mental imagery ability tend to ask participants to generate imagery of everyday scenarios and, then, immediately report the phenomenology of such imagery, in either one sensory modality (Vividness of Visual Imagery Questionnaire) ${ }^{18}$ or multiple sensory modalities (The Plymouth Sensory Imagery Questionnaire). ${ }^{19}$ Alternatively, they may ask respondents to state how frequently they experience imagery during specific daily situations (Spontaneous Use of Imagery Scale). ${ }^{20}$ Such instruments attempt to assess generalized imagery ability, rather than assessing idiosyncratic imagery that may be rich in emotional content and personal relevance, the type that is of particular relevance to psychopathology. In some domains, psychometric measures have been developed to assess recent experiences of specific mental imagery, such as the Craving Experience Questionnaire ${ }^{21}$ and the Motivation Thought Frequency and State Motivation Scales, ${ }^{22}$ which assess the frequency and intensity of imagery associated with craving or motivation.

\section{Laboratory assessments of mental imagery}

Within the laboratory, mental imagery can be evoked and assessed in real time under controlled task conditions. Early experimental studies sought to understand the nature of mental imagery by devising problemsolving tasks that required the use of mental imagery, broken down into distinct components, from generation, maintenance, and inspection to transformation. ${ }^{6}$ Examples of such tasks include mentally visualizing clocks and reporting on the angle between clock hands for various times. ${ }^{23}$ Such tasks have the advantage of offering objective tests of reaction time performance that help to identify the underlying cognitive processes involved.

With the increasing availability of neuroimaging methods such as positron emission tomography (PET) and functional magnetic resonance imaging (fMRI), researchers have been able to more directly compare brain activation during actual sensory perception and the mental imagery of the same information, such as visually presented faces and houses. ${ }^{24}$ However, these tasks are limited in their capacity to investigate mental imagery representations of real-world experiences that have emotional implications for a particular individual. To meet this need, laboratory imagery tasks were developed to assess mental imagery of emotion-provoking situations in everyday life, administered as paper-based instruments (eg, Prospective Imagery Task ${ }^{25}$ ) or as computer tasks that can be completed in the laboratory or inside a brain scanner. $^{26,27}$ Importantly, spontaneous imagery can be assessed under standardized laboratory conditions using adapted mind-wandering paradigms, ${ }^{28}$ which have potential to give further insight into the neurocognitive basis of associative imagery-a form of imagery that has not received sufficient attention to date. For a recent review of mental imagery measures, see Pearson et al., $2013^{29}$.

\section{The Neurocognitive Basis of Mental Imagery}

The nature of mental imagery has been the subject of a long-standing debate in psychological science, ${ }^{30}$ and accounts of the main theoretical debates have been covered extensively. ${ }^{31-33}$ Neuroimaging studies have shown that both visual imagery generation and visual perception involves retinotopic activation of the primary visual cortex. $^{34,35}$ In addition to the visual modality, shared neural activation between actual sensory perception and mental imagery has been found for the auditory and somatosensory modalities. ${ }^{36,37}$ Further, neuronal signals produced by imagined stimuli can integrate with signals generated by real stimuli of a different sensory 
modality, ${ }^{38}$ indicating common cross-modal sensory integration processes between perception and imagery. In consequence, mental imagery can function as a form of "weak perception." 39 Such neurocognitive findings help to explain why mental imagery can simulate past and future experiences in an as-if-real manner. ${ }^{40}$ This key feature of mental imagery is central to its impact on emotion and motivation, which will be discussed later in this article.

While brain regions involved in actual sensory perception and mental imagery overlap substantially, perception is associated with bottom-up "feed-forward" projections from the primary sensory areas, and imagery generation and maintenance are associated with topdown "feedback" projections from the prefrontal cortex and superior parietal areas involved in cognitive control. ${ }^{41,42}$ In addition, mental imagery also recruits neural regions involved in the retrieval of information from long-term memory stores and the maintenance or manipulation of such information in working memory. ${ }^{43,44}$ A corollary is that neural damage to neural regions involved in cognitive control and memory will impair mental imagery functioning.

\section{Impairments in General Mental Imagery Function}

\section{Congenital impairments in imagery generation}

While most individuals can experience mental imagery, reports have emerged in recent years of healthy adults discovering for the first time that, unlike others, they cannot experience mental imagery. Such individuals exhibit severe deficiencies in the ability to remember the past as perceptual experiences ${ }^{45}$ or to construct perceptual simulations of hypothetical future events. ${ }^{46}$ Researchers coined new terms to describe such conditions, namely "aphantasia," ${ }^{46}$ and severely deficient autobiographical memory (SDAM). ${ }^{45}$ Recent psychophysical evidence indicates that such individuals fail to show mental imageryinduced binocular rivalry, suggesting that the observed deficiencies in mental imagery reflect an absence of mental imagery, rather than alternative possibilities such as impaired metacognitive awareness of intact mental imagery. ${ }^{47}$ Interestingly, such individuals report no major functional impairments in daily life and can perform highly on learning and memory tasks using compensatory strategies involving semantic memory ${ }^{45}$ or spatial representation, which may be unimpaired despite the absence of visual images. ${ }^{48}$ Neurocognitive research into aphantasia is at an early stage, and its structural or neuro-functional bases remains to be identified.

\section{Acquired impairments in imagery generation due to neurological disease: the dementias}

Unlike congenital aphantasia, acquired damage to the capacity to generate mental imagery has been observed in neurocognitive disorders. For example, patients with dementia can experience impaired ability to engage in mental imagery simulations of hypothetical future experiences. Dementia reflects a degeneration of neural regions that support the ability to remember past experiences as perceptually and experientially coherent events (episodic memory), including the medial prefrontal and parietal cortices, and temporal regions. ${ }^{43,49-53}$

The capacity to imagine perceptually and experientially coherent hypothetical future experiences (episodic prospection) relies on the ability to extract and recombine relevant contextual and sensory features from memory. ${ }^{54}$ In consequence, both episodic memory and episodic simulation are impaired in dementia. ${ }^{12}$ For example, when asked to recall or imagine an event in as much detail as possible in a three-minute time window, people with Alzheimer's disease (AD) generated fewer event-related visuospatial and contextual perceptual details and experiential details (emotions and thoughts) relative to age-matched healthy controls. ${ }^{55-58}$

Impaired capacity to imagine future events appears to be ubiquitous across dementia subtypes. ${ }^{12}$ For example, patients with semantic dementia, a subtype of frontotemporal dementia that compromises memory of facts and knowledge rather than memory for events (episodic memory), also exhibit impaired ability to imagine hypothetical future events, ${ }^{59}$, presumably because semantic information aids the recall of associated imagery elements and supports the construction of coherent episodic imagery. An impaired ability to imagine future events can cause significant functional impairments to daily life, including impaired decision-making because of insensitivity to future consequences ${ }^{60}$ and a loss of temporally coherent self-identity, ${ }^{55,57}$ which has been linked to suicidality in patients with semantic dementia. ${ }^{61}$ However, the impact of impaired ability to imagine the future on emotional dysregulation and self-regulation in populations with dementia is still not well understood. ${ }^{12}$

\section{Imagery anomalies associated with schizotypy}

There has been significant research interest in the potential relationship between imagery and hallucinations in schizophrenia. ${ }^{62}$ People who score higher on schizotypy questionnaires report greater levels of imagery use in daily life ${ }^{63}$ and greater levels of reliving when asked to retrieve mental imagery of past events. ${ }^{64}$ Furthermore, people with higher schizotypy scores also report a greater tendency to experience imagery-based intrusions after a stressor. ${ }^{65,66}$ Additionally, people who experience hallucinations ${ }^{67}$ or are at high genetic risk for schizophrenia report greater ease of imagery generation and higher vividness of imagery generated in the laboratory. ${ }^{68}$ However, other studies have either found no schizotypy-related differences in the vividness of 
imagery when assessed in the laboratory ${ }^{63}$ or have only observed such effects for imagery of specific sensory modalities ${ }^{64}$ or emotional tone. ${ }^{63}$

In tasks in which pictures and written words are presented for encoding, followed by a surprise test of recognition memory, people who experience visual hallucinations were more likely to misremember verbally presented information as having been visually presented. ${ }^{63}$ This error has been observed in patients with schizophrenia who experience visual hallucinations, relative to patients with schizophrenia who do not experience visual hallucinations ${ }^{13,69}$ or healthy individuals. ${ }^{13}$ Such results have been attributed to the presence of vivid visual imagery representations of the information presented, leading to impaired encoding or retrieval of the source information. An argument has been made that confusion between internal and external stimuli may also occur during perception, contributing to the experience of hallucinations in both schizophrenia 70 and other conditions such as Parkinson's disease (PD). ${ }^{71}$ While this hypothesis is plausible, direct evidence for the confusion between mental imagery and actual sensory perception is still required.

Heightened imagery strength appears unlikely to be a contributor to sensory hallucinations. Consistent with the presence of deficits in executive function in schizophrenia, ${ }^{72}$ the retrieval and generation of imagery are often impaired. ${ }^{73,74}$ Studies using objective measures of mental imagery ability (such as mental rotation) have found little relationship between auditory hallucinations and imagery vividness in schizophrenia. ${ }^{62}$ Importantly, relative to healthy controls, the higher vividness of deliberately generated mental imagery appears to be unrelated to hallucination frequency in patients with schizophrenia, ${ }^{75,76}$ relatives of these patients, and people with high schizotypy. ${ }^{76}$ However, it may be premature to say that the issue is completely resolved. For example, the heightened vividness of deliberately generated imagery may not relate to hallucination frequency, but the heightened vividness of spontaneously generated imagery may contribute to reality-monitoring errors. Future studies could investigate schizotypylinked individual differences in the vividness of spontaneously generated imagery that is assessed under standardized laboratory conditions (eg, using adapted mind-wandering paradigms ${ }^{28}$ ).

\section{Mood and anxiety disorders}

Impaired general imagery generation ability in anxious individuals ${ }^{77}$ and reduced imagery generation and manipulation ability in depression have been demonstrated. ${ }^{78}$ A more recent comprehensive assessment revealed no deficits in the ability to generate, manipulate, or recall images in people with bipolar disorder, major depression, or anxiety disorders relative to healthy controls matched on socio-demographic factors. ${ }^{79}$ More isolated imagery generation deficits have been reported in anxiety disorders, concerning the ability to generate event-related details of future simulations. ${ }^{80}$ However, mental imagerylinked dysfunction in mood and anxiety disorders appears to be primarily linked to its emotional amplification effects when the content of cognition is emotion laden, which is discussed in more detail in the following section.

\section{The Impact of Mental Imagery on Emotion and Motivation}

In addition to impairments in the general capacity to generate mental imagery or to discriminate it from actual sensory perception, anomalies in imagery-based emotionladen cognition are of importance to mental disorders because of its impact on emotion and motivation.

\section{Mental imagery can evoke strong emotional responses}

Many experimental studies have demonstrated that mental imagery can evoke emotional responses at subjective and physiological levels. ${ }^{40}$ For example, in healthy people, imagining fear and anger-related situations leads to heart rate acceleration ${ }^{81,82}$; increased skin conductance ${ }^{83,84}$ and potentiation of the startle blink reflex $^{81,85}$ relative to imagining emotionally neutral stimuli.

At the neural level, fMRI studies on the visual imagery of emotional stimuli have found patterns of activation akin to those found during visual perception of the same stimuli. For example, the nucleus accumbens (NAcc) and medial prefrontal cortex (mPFC) are selectively activated during both visual perception ${ }^{86}$ and visual imagery of emotionally positive scenes. ${ }^{87}$ The amygdala can also be activated during both visual perception ${ }^{88}$ and visual imagery $^{87,88}$ of emotionally positive and negative scenes or faces. Finally, fMRI studies using real-time neural activation feedback show that, over successive trials, participants were able to use idiosyncratic mental imagery of positive and negative scenarios to regulate activation of emotion processing regions such as the insula. ${ }^{89}$

\section{The functional impact of imagery on emotion}

To investigate whether imagery plays a functional role in eliciting emotional responses, researchers have interfered with imagery generation and tested whether such interference leads to reductions in imagery vividness and emotional impact. Typically, studies have employed a concurrent task to reduce the availability of the visuospatial working memory resources required for visual mental imagery generation. For example, Andrade and colleagues had participants generate mental imagery in response to emotional cues, and those who engaged in 
simultaneous finger tapping of a spatial pattern reported lower vividness of mental imagery than those who did not perform a concurrent task. ${ }^{90}$ Importantly, the reduction in imagery vividness accompanied a corresponding decline in the intensity of the emotional response to the negative imagery. This result was replicated using concurrent eye movements, instead of finger tapping, during repeated emotional memory imagery generation. $^{91}$ Other researchers have likewise shown that similar types of concurrent task interference can reduce the emotional impact of imagery representing feared future events in healthy and clinical samples. ${ }^{92-94}$

Researchers have also tested the impact of visuospatial interference on the frequency of negative intrusive mental imagery. There is growing evidence that playing the visuospatial computer game, Tetris, ${ }^{95}$ following exposure to analog trauma film clips depicting traumatic scenes reduces the frequency of subsequent involuntary memory imagery of the trauma film. ${ }^{96}$ For example, in an early study, healthy people either played Tetris or not after viewing the traumatic film and reported intrusive imagery of the film clip content in a diary over the following week. ${ }^{97}$ Those who played Tetris after the film reported experiencing fewer imagery intrusions and distress than those who had not. ${ }^{97}$ Recent proof of concept studies moving from the lab to the clinic show that a visuospatial interference task, relative to a control task, led to reductions in the frequency of negative intrusive mental imagery when administered soon after a road traffic accident ${ }^{98}$ or traumatic childbirth. ${ }^{99}$

\section{Mental imagery as an emotional amplifier: a comparison with verbal-linguistic cognition}

The abovementioned findings showed that mental imagery can evoke emotional responses may be because of the emotional content of imagined stimuli, rather than because of the imagery representation of such stimuli. Several studies have sought to address this question by comparing the relative emotional impact of imagerybased and verbal-linguistic representations of the same information. In one study, healthy participants were instructed to either generate imagery or focus on the semantic meaning of initially ambiguous auditory scenarios that ended negatively (eg, "You are at work when you hear the fire alarms go off. You run to the exit to discover that it is . . . for real"). ${ }^{5}$ Participants in the imagery condition reported greater increases in selfreported anxiety than the verbal condition. ${ }^{5}$ This finding has since been replicated by subsequent studies that found imagery representations to have evoked greater emotional impact than did verbal-linguistic representations of negative information ${ }^{100-102}$ and positive information. ${ }^{100,103}$ Researchers have, therefore, proposed that mental imagery can amplify the impact of cognition on emotion and exacerbate mood instability in both negative and positive directions, such as in bipolar disorder. $^{104}$

\section{The impact of emotional, mental imagery on motivation}

Functional theories of emotion postulate that emotions serve to motivate approach and avoidance behavior in response to appetitive and aversive cues, where cues can be internal cognition or stimuli in the environment. ${ }^{105,106}$ For appetitive or aversive stimuli, the moment-to-moment experience of being motivated to approach or avoid such stimuli involves emotionally charged cognition. ${ }^{107}$ Mental imagery representations of appetitive stimuli can evoke intense desires or craving for, and motivation to acquire, such stimuli.

For example, higher levels of vividness of food imagery are associated with more intense craving for the imagined food item, ${ }^{108}$ and such effects are amplified in dieters. ${ }^{109}$ The vividness of imagery concerning a wide range of other substances and activities are also positively related to the intensity of desires to consume the imagined substances or to engage in the imagined activities. ${ }^{110}$ Similarly, in cigarette smokers, instructions to generate smoking-related imagery is reliably associated with significant increases in self-reported craving, ${ }^{111,112}$ comparable to those from in-vivo exposure to cigarettes. ${ }^{113}$ However, direct comparisons of mental imagery and smoking cues show stronger effects from lighting a cigarette than from smoking-related imagery, ${ }^{114}$ consistent with the idea that mental imagery functions as a weak form of actual sensory perception. ${ }^{39}$

Physiologically, evoking mental imagery of food has been shown to modulate the gustatory salivary reflex (salivary $\mathrm{pH}$ levels) in a similar way to having participants process the sensory qualities of real food. ${ }^{115}$ Furthermore, repetitive mental imagery concerning food consumption has been shown to produce satiation. ${ }^{116}$

Neuroimaging evidence also corroborates the role of mental imagery in addiction-related processes. For example, in individuals with cocaine addiction, neural activation during mental imagery of personalized drug use, as compared with anger-related mental imagery, is associated with greater activation in the limbic, paralimbic, and striatal brain regions, which are involved in reward learning, wanting, and anticipation. ${ }^{117}$

In the natural environment, craving-related imagery is typically evoked by associated cues in the form of internal cognition or environmental stimuli. The anticipated pleasure or relief provided by imagery of the desired substance leads to the further elaboration of such imagery, ${ }^{11,107}$ which may reduce the level of cognitive resources available for performing other cognitive tasks, particularly those requiring visuospatial working memory. ${ }^{118}$ 


\section{The functional impact of imagery on motivation}

A range of concurrent visuospatial tasks has been used to reduce craving by disrupting imagery of desired stimuli, including lateral eye movements, ${ }^{119}$ the elicitation of competing mental imagery, ${ }^{120}$ playing Tetris, ${ }^{121}$ and modeling clay. ${ }^{122}$ Reductions in craving have also been observed from the use of more passive tasks such as viewing changing visual patterns on a screen such as "dynamic visual noise"123,124 or scanning bodily sensations. ${ }^{125}$ Such results provide evidence that imagery representations of desired stimuli have a causal impact on approach motivation for such stimuli.

Contexts in which concurrent task interference do not reduce craving are also illuminating. For example, focusing on abdominal sensations, ${ }^{126}$ inhaling a sweet scent during imagery of desired food items, ${ }^{127}$ or completing a concurrent verbal working memory task 122 do not reduce craving. Successful disruption of cravings induced by imagining the desired stimuli appears to require tasks that tax the same sensory domains as those involved in cravings induced by actual encounters with the stimuli. In the case of coffee ${ }^{128}$ and cigarettes, ${ }^{129}$ both concurrent visual and olfactory imagery are effective at reducing craving. However, concurrent auditory imagery does not interfere with cravings for food ${ }^{130}$ or coffe ${ }^{128}$ that is consistent with observations that sound is not a prominent feature in desires for these targets. ${ }^{110}$

In summary, evidence suggests that mental imagerybased cognitions are involved in emotional and motivational processing, and comparative data with verbal-linguistic cognition suggest that imagery has a greater impact on emotional and motivational outcomes. Interfering with imagery of desired stimuli weakens its emotional and motivational impact, providing persuasive evidence of a causal relationship between mental imagery and its emotional and motivational response.

\section{Emotional, Mental imagery-linked Dysfunction in Psychopathology}

Given the capacity of mental imagery to impact emotion and motivation, anomalies in the occurrence of emotional mental imagery may contribute to psychopathology in a transdiagnostic manner. This section reviews current evidence linking anomalies in the occurrence of mental imagery to emotional, motivational, and behavioral dysfunction through the example of several mental disorders.

\section{Anxiety disorders}

Elevated anxiety appears to be linked to elevated levels of vividness of negative future imagery ${ }^{131,132}$ and a greater ease of generating negative future imagery relative to nonnegative future imagery. ${ }^{80} \mathrm{In}$ a sample of people with mood and anxiety disorders, higher anxiety levels corresponded with higher levels of negative future imagery vividness and higher sensations of "as-if-real" pre-experiencing of the imagined negative future event. ${ }^{79}$

Unwanted mental imagery that comes to mind unbidden is prevalent in anxiety disorders. ${ }^{133}$ For example, intrusions of trauma-related scenes in PTSD,${ }^{134}$ typically triggered by sensory stimuli associated with the trauma, are a core symptom that causes significant distress, anxiety, and avoidance behaviors that impair daily functioning. ${ }^{135,136}$ Similarly, mental imagery of feared contamination scenes in obsessivecompulsive disorder (OCD) is highly prevalent and is associated with distress, anxiety, and compulsive washing. ${ }^{137}$ In social anxiety, individuals often experience mental imagery of themselves committing a social gaffe or appearing anxious to observers, with such imagery eliciting subjective anxiety and distress. ${ }^{138}$

Generalized anxiety disorder (GAD) is characterized by repetitive self-referential negative verbal styles of thinking, such as worry. ${ }^{139}$ Researchers have proposed that people with GAD worry in verbal form to avoid the highly emotional and physiologically arousing negative imagery of feared outcomes. ${ }^{140}$ Experimental evidence provides support for this account, as inducing repeated verbal thinking of hypothetical future events leads increased abstractness of thought content and reduced imagery over time. ${ }^{141}$ However, while repetitive abstract verbal thinking about feared outcomes lowers fear and anxiety initially, it is followed by increases in anxiety that coincide with the occurrence of imagery. ${ }^{141}$

Another way in which mental imagery may contribute to dysfunctional avoidance behaviors that sustain anxiety, such as in phobias, is through aversive conditioning. Dadds and colleagues investigated individual differences in imagery ability and the tendency to report specific aversions such as phobias of certain foods. ${ }^{142}$ Results indicated that higher imagery ability was associated with higher levels of aversion, even after controlling for potential confounders such as proneness to disgust. ${ }^{142}$ Presumably, a greater ability to engage in the imagery of food consumption may strengthen the learned associations between the food stimuli and disgust, ${ }^{143}$ contributing to avoidance of the food item and, thereby, maintaining the phobia.

In summary, emotional, mental imagery could maintain anxiety either directly through vivid imagery of aversive scenarios or intrusive traumatic imagery or indirectly through avoidance of aversive images that sustains avoidance behaviors, maintaining anxiety.

\section{Mood disorders: major depressive disorder}

Depression has been associated with the elevated occurrence of emotionally distressing mental imagery and reduced occurrence of positive mental imagery. ${ }^{144}$ 
For example, in community samples, depressive symptoms are related to higher frequencies of negative mental imagery and less frequent experiences of positive imagery. ${ }^{145}$ When instructed to imagine negative and positive personal future events within different time periods, individuals with major depression are found to generate fewer positive, but not negative, future events relative to healthy controls. ${ }^{146-148}$

Investigators have also examined depression-linked biases in phenomenological aspects such as imagery vividness. When instructed to generate imagery in response to verbal sentences describing positive and negative future situations, people dysphoria, ${ }^{25,149}$ major depression, ${ }^{130}$ and major depression with acquired brain injury $(\mathrm{ABI})^{150}$ report lower vividness for imagery of positive relative to negative future events, as compared with healthy controls. In patients with $\mathrm{ABI}$, a reduced capacity to anticipate positive relative to negative future events and reduced imagery vividness of positive relative to negative future events, as compared with healthy controls, was uniquely found in patients with $\mathrm{ABI}$ and depression, but not patients with $\mathrm{ABI}$ without major depression. ${ }^{150}$ Further, reduced positive imagery vividness appears to be uniquely associated with depression, not anxiety, in adolescence. ${ }^{132}$

In addition to anomalies in deliberately generated emotional imagery, patients with depression tend to report frequent experiences involving unwanted mental imagery in the form of spontaneously occurring emotionally aversive mental imagery of past and future experiences. ${ }^{151}$ Recent laboratory research has shown that higher scores on the Beck Depression Inventory-II (BDIII) are associated with lower tendencies to spontaneously imagine positive relative to negative aspects of the future during mind-wandering. ${ }^{28}$ Such anomalies in mental imagery-based cognition are postulated to maintain the depression-linked elevation of negative emotional states and attenuation of positive emotional states. ${ }^{144}$

At present, there is little research linking impoverished positive mental imagery to anhedonia (loss of interest and motivation in rewarding experiences), a core symptom of depression. However, results from a treatment study suggested that, for people with clinical levels of depression, four weeks of positive mental imagery training resulted in a faster and greater recovery of reengagement in daily activities than in a non-imagery active control condition, ${ }^{152}$ indicating that positive mental imagery-based manipulations may enhance behavioral activation in depression.

\section{Mood disorders: bipolar disorder}

Patients with bipolar disorder also have highly vivid negative future imagery, and vividness is higher in those with a more unstable course of the disorder. ${ }^{153}$ Unlike major depression, bipolar disorder is associated with the presence of vivid positive imagery at times of high positive affect. ${ }^{154}$ Hypomania is associated with intrusive positive imagery about future events ${ }^{155}$ and a greater tendency to use imagery in daily life. ${ }^{156}$ In a laboratory study, hypomanic traits predicted greater emotional response to positive mental imagery in adolescents. ${ }^{157}$ The bipolar phenotype appears to be associated with greater vividness and emotional response to both negative and positive mental imagery, which is postulated to exacerbate mood oscillations ${ }^{103}$ and maladaptive approach-related behaviors in bipolar disorder. ${ }^{157}$ While preliminary evidence suggests that mood lability is associated with greater vividness and self-involvement of mental imagery across mood and anxiety disorders, ${ }^{79}$ further experimental research is required to investigate possible downstream impacts on behavior in bipolar disorder.

In summary, anomalies in the strength and occurrence of positive and negative mental imagery can contribute to mood dysregulation and mood instability in a transdiagnostic manner.

\section{Non-suicidal self-injury and suicidal behavior}

Mental imagery of self-harm has been linked to nonsuicidal self-injury (NSSI). One study surveyed NSSI cognition and behavior in college students and found the occurrence of NSSI mental imagery of past NSSI acts frequently preceded NSSI behavior, particularly while the urge to self-harm is strong. ${ }^{158}$ Specific characteristics of self-harm imagery may relate to acting or not acting on the self-harm urges, depending on whether the imagery was appraised as aversive or comforting. ${ }^{158}$ These findings indicate that emotion-laden mental imagery of self-harm may play a role in motivating approach behaviors toward, or avoidance behaviors from, self-harm. ${ }^{159}$

In addition to NSSI, compelling intrusions of imagined suicidal acts (suicide "flash-forwards") ${ }^{160}$ are often reported by people with major depression ${ }^{160,161}$ and individuals with bipolar disorder. ${ }^{153}$ Consistent with the Interpersonal Theory of Suicide, ${ }^{162}$ graphic mental imagery of suicide may facilitate suicidal behavior by contributing to the process of habituating to the painful and fearful aspects of death by suicide and by facilitating planning, rehearsal, and action readiness. ${ }^{161}$ Accordingly, cross-sectional research in college samples has reported associations between frequent and vivid suicide-related mental imagery and higher levels of suicidal intent ${ }^{163}$ or past suicidal behavior. ${ }^{164}$ Importantly, in a recent longitudinal study in a Chinese in-patient sample, the occurrence of suicidal "flash-forwards" significantly predicted suicidal intent at both baseline and 7 weeks, ${ }^{165}$ and suicidal imagery was among the factors differentiating suicidal intent from suicidal attempts in a representative sample of young adults. ${ }^{166}$ 


\section{Substance-related and addictive disorders}

As previously noted, more vivid imagery is associated with more intense craving-a diagnostic feature of addictions (DSM-V) ${ }^{134}$ During treatment for alcohol abuse or dependence, a study found that $81 \%$ of participants reported experiencing imagery associated with craving. ${ }^{167}$ Importantly, this mental imagery was not just visual in modality, as taste imagery was also prominent, providing a unique contribution to the prediction of craving strength. ${ }^{167}$

Mental imagery can also amplify cravings elicited by other factors such as physiological withdrawal. For example, smoking urges in both cigarette-deprived and non-deprived groups are accentuated by experimentally inducing mental imagery of cigarettes. ${ }^{113}$ However, if the person is attempting to abstain from acquisition or consumption of the desired stimuli, imagery-induced craving also elicits anxiety. ${ }^{168}$

The relationship between the imagery of appetitive stimuli and approach behavior toward such stimuli is complex. While simple actions such as lighting a cigarette, or more complex habitual chains of actions, may become automated and directly activated by environmental cues without conscious cognition, ${ }^{169}$ most cases of substance use involve some degree of conscious planning or context-specific modification of behavior (eg, finding a tobacco outlet). ${ }^{107}$ Conscious planning and behavioral modification are more likely to occur when craving intensity is high, that is, in turn, associated with more vivid and frequent imagery of the desired stimuli. ${ }^{11}$

Of course, the effects of desires on behavior are constrained by additional factors such as stimuli availability, self-control, and the strength of countervailing goals desires. ${ }^{107}$ Despite such constraints, the frequency of alcohol imagery accounted for $16 \%$ of the variance in monthly alcohol consumption in young adults. ${ }^{170}$ The frequency of craving imagery also predicts relapse and treatment dropout in inpatients being treated for alcohol dependence. ${ }^{171}$ Therefore, the occurrence of craving imagery holds important implications for high-risk approach behaviors in addiction.

\section{Future Directions}

Evidence of the link between mental imagery-based cognition and emotional, motivational, and behavioral dysfunction across several categories of mental disorders strongly suggests that clinical assessment should focus on the content and format of cognition.

One important reason for assessing both the content of cognition and the format of cognition is that frequent and vivid mental imagery may be a key factor behind the progression from ideation to action. The clinical implications of not assessing imagery have been highlighted in the field of suicidal behavior, in which missed identification of imagery of suicidal action means neglecting an index of progression to a potential attempt. ${ }^{166}$ Future research should further investigate the link between mental imagery and emotionally charged risky behaviors such as NSSI, mania, aggression, and addiction.

A second reason to assess mental imagery is that we need to obtain a better understanding of the neurocognitive bases of imagery representations of salient stimuli that contribute to psychopathology. Initial advances have been made in exploring the basis of trauma flashbacks ${ }^{172}$ and also of elevated emotional imagery in bipolar disorder. ${ }^{27}$ Future research should continue to focus on delineating the precise neural substrates and cognitive processes involved in emotionally charged mental imagery and how such processes are disrupted in psychopathology.

While this review has focused on mental imagery representations that play a role in emotional and motivational dysfunction, mental imagery can also be a powerful lever toward wellbeing and adaptive behavior. ${ }^{173}$ There has been recent growing interest in developing imagery-based interventions that could train individuals to use positive imagery to improve mood, ${ }^{174}$ and the use of soothing imagery is already part of cognitive therapy approaches for depression, trauma, and personality disorders. ${ }^{175,176}$ Research on positive imagery has also demonstrated the importance of fostering motivation for functional goals such as weight reduction. ${ }^{177}$ The emotional and motivational power of mental imagery suggests that these examples will be precursors of other, highly innovative applications of mental imagery to treatment.

\section{Conclusions}

Mental imagery-based cognition is of significant conceptual and clinical relevance to psychiatry and allied disciplines. Mental imagery is core to our capacity to reexperience past events and pre-experience future ones, affording it the power to impact emotion, motivation, and behavior. Through the examples of mood and anxiety disorders, self-injury, and addiction, this review aimed to characterize mental imagery-linked dysfunction as extending beyond the contexts of neurocognitive impairment. When problematic cognition occurs in mental imagery form, its impact on emotion, motivation, and behavior is amplified, which serves to maintain and exacerbate psychopathology and dysfunction. Therefore, mental imagery is an important target for clinical assessment across mental disorders, and a deeper understanding of mental imagery-linked dysfunction has the potential to drive the development of algorithms to aid treatment decision-making and inform transdiagnostic treatment innovation. 


\section{Disclosure}

Julie Ji was supported by the Forrest Research Foundation. Emily Holmes was supported by the Karolinska Institutet and the Swedish Research Council (VR). Colin MacLeod, David Kavanagh, and Martina Di Simplicio have nothing to disclose.

\section{REFERENCES:}

1. Kosslyn SM, Ganis G, Thompson WL. Neural foundations of imagery. Nat Rev Neurosci. 2001; 2(9): 635-642.

2. Kosslyn SM, Seger C, Pani JR, Hillger LA. When is imagery used in everyday life? A diary study. J Ment Imagery. 1990; 14(3-4): 131-152.

3. Byrne P, Becker S, Burgess N. Remembering the past and imagining the future: a neural model of spatial memory and imagery. Psychol Rev. 2007; 114(2): 340-375.

4. Dils AT, Boroditsky L. Visual motion aftereffect from understanding motion language. Proc Natl Acad Sci USA. 2010; 107(37): 16396-16400.

5. Holmes EA, Mathews A. Mental imagery and emotion: a special relationship? Emotion. 2005; 5(4): 489-497.

6. Kosslyn SM. Image and Brain: The Resolution of the Imagery Debate. Cambridge, MA: MIT Press; 1994.

7. Taylor SE, Pham LB, Rivkin ID. Armor D a. Harnessing the imagination. Am Psychol. 1998; 53(4): 429-439.

8. Seligman MEP, Railton P, Baumeister RF, Sripada C. Navigating Into the Future or Driven by the Past. Perspect Psychol Sci. 2013; 8(2): 119-141.

9. Moulton ST, Kosslyn SM. Imagining predictions: mental imagery as mental emulation. Philos Trans R Soc Lond B Biol Sci. 2009; 364(1521): 1273-1280.

10. Di Simplicio M, McInerney JE, Goodwin GM, Attenburrow M-J, Holmes EA. Revealing the mind's eye: bringing (mental) images into psychiatry. Am J Psychiatry. 2012; 169(12): 1245-1246.

11. May J, Kavanagh DJ, Andrade J. The Elaborated Intrusion Theory of desire: a 10-year retrospective and implications for addiction treatments. Addict Behav. 2015; 44(suppl C): 29-34.

12. Irish M, Piolino P. Impaired capacity for prospection in the dementias-theoretical and clinical implications. Br J Clin Psychol. 2016; 55(1): 49-68.

13. Brébion G, Ohlsen RI, Pilowsky LS, David AS. Visual hallucinations in schizophrenia: confusion between imagination and perception. Neuropsychology. 2008; 22(3): 383-389.

14. Di Simplicio M, McInerney JE, Goodwin GM, Attenburrow MJ, Holmes EA. Revealing the mind's eye: bringing (mental) images into psychiatry. Am J Psychiatry. 2012; 169(12): 1245-1246.

15. Kahneman D. Experienced utility and objective happiness: A moment-based approach. In: Kahneman D, Tversky A, eds. Choices, Values and Frames. New York: Cambridge University Press; 2003.

16. Boukhechba M, Gong J, Kowsari K, et al. Physiological changes over the course of cognitive bias modification for social anxiety. In: 2018 IEEE EMBS International Conference on Biomedical \& Health Informatics (BHI). 2018: 422-425

17. Chow PI, Fua K, Huang Y, et al. Using Mobile Sensing to Test Clinical Models of Depression, Social Anxiety, State Affect, and Social Isolation Among College Students. Calvo R, ed. J Med Internet Res. 2017; 19(3): e62.

18. Marks DF. Visual imagery differences in the recall of pictures. Br J Psychol. 1973; 64(1): 17-24.

19. Andrade J, May J, Deeprose C, Baugh S-J, Ganis G. Assessing vividness of mental imagery: The Plymouth Sensory Imagery Questionnaire. Br J Psychol. 2014; 105(4): 547-563.
20. Reisberg D, Pearson DG, Kosslyn SM. Intuitions and introspections about imagery: the role of imagery experience in shaping an investigator's theoretical views. Appl Cogn Psychol. 2003; 17(2): 147-160.

21. May J, Andrade J, Kavanagh DJ, et al. The craving experience questionnaire: a brief, theory-based measure of consummatory desire and craving. Addiction. 2014; 109(5): 728-735.

22. Kavanagh DJ, Robinson N, Connolly J, Connor J, Andrade J, May J The revised four-factor motivational thought frequency and state motivation scales for alcohol control. Addict Behav. 2018; 87: 69-73.

23. Paivio A. Comparisons of mental clocks. J Exp Psychol Hum Percept Perform. 1978; 4(1): 61-71.

24. O'Craven KM, Kanwisher N. Mental imagery of faces and places activates corresponding stiimulus-specific brain regions. J Cogn Neurosci. 2000; 12(6): 1013-1023.

25. Holmes EA, Lang TJ, Moulds ML, Steele AM. Prospective and positive mental imagery deficits in dysphoria. Behav Res Ther. 2008; 46(8): 976-981.

26. Szpunar KK, Schacter DL. Get real: effects of repeated simulation and emotion on the perceived plausibility of future experiences. $J$ Exp Psychol Gen. 2013; 142(2): 323-327.

27. Di Simplicio M, Alfarano G, Ji JL, Suri S, Visser RM, Holmes EA. Neural activity during simulation of future negative scenarios in individuals with bipolar disorder phenotype. (In prep).

28. Ji JL, Holmes EA, MacLeod C, Murphy FC. Spontaneous cognition in dysphoria: reduced positive bias in imagining the future. Psychol Res. 2018

29. Pearson DG, Deeprose C, Wallace-Hadrill SMA, Burnett Heyes S, Holmes EA. Assessing mental imagery in clinical psychology: a review of imagery measures and a guiding framework. Clin Psychol Rev. 2013; 33(1): 1-23.

30. Galton F. Psychometric experiments. Brain. 1879; 2(2): 149-162.

31. Pearson J, Kosslyn SM. The heterogeneity of mental representation: ending the imagery debate. Proc Natl Acad Sci USA. 2015; 112(33): 10089-10092.

32. Barsalou LW. Grounded cognition. Annu Rev Psychol. 2008 59(1): 617-645

33. Pylyshyn ZW. What the mind's eye tells the mind's brain: A critique of mental imagery. Psychol Bull. 1973; 80(1): 1-24.

34. Dijkstra N, Zeidman P, Ondobaka S, van Gerven MAJ, Friston K. Distinct top-down and bottom-up brain connectivity during visual perception and imagery. Sci Rep. 2017; 7(1): 5677.

35. Slotnick SD, Thompson WL, Kosslyn SM. Visual mental imagery induces retinotopically organized activation of early visual areas. Cereb Cortex. 2005; 15(10): 1570-1583.

36. Ehrsson HH, Geyer S, Naito E. Imagery of voluntary movement of fingers, toes, and tongue activates corresponding body-part-specific motor representations. J Neurophysiol. 2003; 90(5): 3304-3316.

37. Hubbard TL. Auditory imagery: empirical findings. Psychol Bull. 2010; 136(2): 302-329.

38. Berger CC, Ehrsson HH. Mental imagery induces cross-modal sensory plasticity and changes future auditory perception. Psychol Sci. 2018; 29(6): 926-935.

39. Pearson J, Naselaris T, Holmes EA, Kosslyn SM. Mental imagery: functional mechanisms and clinical applications. Trends Cogn Sci. 2015; 19(10): 590-602.

40. Ji JL, Heyes SB, MacLeod C, Holmes EA. Emotional mental imagery as simulation of reality: fear and beyond-a tribute to Peter Lang. Behav Ther. 2016; 47(5): 702-719.

41. Stokes M, Thompson R, Cusack R, Duncan J. Top-down activation of shape-specific population codes in visual cortex during mental imagery. J Neurosci. 2009; 29(5): 1565 LP-1572.

42. Mechelli A, Price CJ, Friston KJ, Ishai A. Where bottom-up meets top-down: neuronal interactions during perception and imagery. Cereb Cortex. 2004; 14(11): 1256-1265. 
43. Schacter DL, Addis DR, Buckner RL. Remembering the past to imagine the future: the prospective brain. Nat Rev Neurosci. 2007; 8(9): 657-661.

44. Baddeley $\mathrm{AD}$, Andrade J. Working memory and the vividness of imagery. J Exp Psychol Gen. 2000; 129(1): 126-145.

45. Palombo DJ, Alain C, Söderlund H, Khuu W, Levine B. Severely deficient autobiographical memory (SDAM) in healthy adults: A new mnemonic syndrome. Neuropsychologia. 2015; 72(suppl C): 105-118.

46. Zeman A, Dewar M, Della Sala S. Lives without imagery congenital aphantasia. Cortex. 2015; 73(suppl C): 378-380.

47. Keogh R, Pearson J. The perceptual and phenomenal capacity of mental imagery. Cognition. 2017; 162:124-132.

48. Keogh R, Pearson J. The blind mind: no sensory visual imagery in aphantasia. Cortex. 2018; 105:53-60.

49. Buckner RL, Snyder AZ, Shannon BJ, et al. Molecular, structural, and functional characterization of Alzheimer's disease: evidence for a relationship between default activity, amyloid, and memory. $J$ Neurosci. 2005; 25(34): 7709 LP-7717.

50. Addis DR, Wong AT, Schacter DL. Remembering the past and imagining the future: common and distinct neural substrates during event construction and elaboration. Neuropsychologia. 2007; 45(7): 1363-1377.

51. Hassabis D, Kumaran D, Vann SD, Maguire EA. Patients with hippocampal amnesia cannot imagine new experiences. Proc Natl Acad Sci USA. 2007; 104(5): 1726-1731.

52. Okuda J, Fujii T, Ohtake H, et al. Thinking of the future and past: the roles of the frontal pole and the medial temporal lobes. Neuroimage. 2003 ; 19(4): 1369-1380.

53. Szpunar KK, Watson JM, McDermott KB. Neural substrates of envisioning the future. Proc Natl Acad Sci USA. 2007; 104(2): 642-647.

54. Addis DR, Schacter DL. Constructive episodic simulation: temporal distance and detail of past and future events modulate hippocampal engagement. Hippocampus. 2008; 18(2):227-237.

55. Addis DR, Sacchetti DC, Ally BA, Budson AE, Schacter DL. Episodic simulation of future events is impaired in mild Alzheimer's disease. Neuropsychologia. 2009; 47(12): 2660-2671.

56. Irish M, Halena S, Kamminga J, Tu S, Hornberger M, Hodges JR. Scene construction impairments in Alzheimer's disease - A unique role for the posterior cingulate cortex. Cortex. 2015; 73(suppl C): 10-23.

57. Irish M, Addis DR, Hodges JR, Piguet O. Exploring the content and quality of episodic future simulations in semantic dementia. Neuropsychologia. 2012; 50(14): 3488-3495.

58. Irish M, Hodges JR, Piguet O. Episodic future thinking is impaired in the behavioural variant of frontotemporal dementia. Cortex. 2013; 49(9): 2377-2388.

59. Irish M, Piguet $\mathrm{O}$. The pivotal role of semantic memory in remembering the past and imagining the future. Front Behav Neurosci. 2013; 7: 27.

60. Bechara A, Tranel D, Damasio H. Characterization of the decisionmaking deficit of patients with ventromedial prefrontal cortex lesions. Brain. 2000; 123(Pt 11): 2189-2202.

61. Hsiao JJ, Kaiser N, Fong SS, Mendez MF. Suicidal behavior and loss of the future self in semantic dementia. Cogn Behav Neurol. 2013; 26(2): 85-92.

62. Seal ML, Aleman A, McGuire PK. Compelling imagery, unanticipated speech and deceptive memory: neurocognitive models of auditory verbal hallucinations in schizophrenia. Cogn Neuropsychiatry. 2004; 9(1-2): 43-72.

63. Aynsworth C, Nemat N, Collerton D, Smailes D, Dudley R. Reality monitoring performance and the role of visual imagery in visual hallucinations. Behav Res Ther. 2017; 97: 115-122.

64. Winfield H, Kamboj SK. Schizotypy and mental time travel. Conscious Cogn. 2010; 19(1): 321-327.
65. Holmes EA, Steel C. Schizotypy: a vulnerability factor for traumatic intrusions. J Nerv Ment Dis. 2004; 192(1): 28-34.

66. Steel C, Fowler D, Holmes EA. Trauma-related intrusions and psychosis: an information processing account. Behav Cogn Psychother. 2005; 33(2): 139-152.

67. Barrett TR. Verbal hallucinations in normals-II: self-reported imagery vividness. Pers Individ Dif. 1993; 15(1): 61-67.

68. Crespi B, Leach E, Dinsdale N, Mokkonen M, Hurd P. Imagination in human social cognition, autism, and psychotic-affective conditions. Cognition. 2016; 150: 181-199.

69. Brébion G, Ohlsen RI, Bressan RA, David AS. Source memory errors in schizophrenia, hallucinations and negative symptoms: a synthesis of research findings. Psychol Med. 2012; 42(12): 2543-2554.

70. Bentall RP, Baker GA, Havers S. Reality monitoring and psychotic hallucinations. Br J Clin Psychol. 1991; 30(Pt 3): 213-222.

71. Barnes J, Boubert L, Harris J, Lee A, David AS. Reality monitoring and visual hallucinations in Parkinson's disease. Neuropsychologia. 2003; 41(5): 565-574.

72. Keefe RSE, Harvey PD. Cognitive impairment in schizophrenia bt novel antischizophrenia treatments. In: Geyer MA, Gross G, eds. Berlin, Heidelberg: Springer Berlin Heidelberg; 2012: 11-37.

73. D'Argembeau A, Raffard S, Van der Linden M. Remembering the past and imagining the future in schizophrenia. J Abnorm Psychol. 2008; 117(1): 247-251.

74. Steel C, Wykes T, Ruddle A, Smith G, Shah DM, Holmes EA. Can we harness computerised cognitive bias modification to treat anxiety in schizophrenia? A first step highlighting the role of mental imagery. Psychiatry Res. 2010; 178(3): 451-455.

75. Sack AT, van de Ven VG, Etschenberg S, Schatz D, Linden DEJ. Enhanced vividness of mental imagery as a trait marker of schizophrenia? Schizophr Bull. 2005; 31(1): 97-104.

76. Oertel V, Rotarska-Jagiela A, van de Ven V, et al. Mental imagery vividness as a trait marker across the schizophrenia spectrum. Psychiatry Res. 2009; 167(1-2): 1-11.

77. Morrison AS, Amir N, Taylor CT. A behavioral index of imagery ability in social anxiety. Cognit Ther Res. 2011; 35(4): 326-332.

78. Zarrinpar A, Deldin P, Kosslyn SM. Effects of depression on sensory/motor vs. central processing in visual mental imagery. Cogn Emotion. 2006; 20(6): 737-758.

79. Di Simplicio M, Renner F, Blackwell SE, et al. An investigation of mental imagery in bipolar disorder: Exploring "the mind's eye". Bipolar Disord. 2016; 18(8): 669-683.

80. Wu JQ, Szpunar KK, Godovich SA, Schacter DL, Hoffman SG. Episodic future thinking in generalized anxiety disorder. 2016; (617): 1-8.

81. Vrana SR, Lang PJ. Fear imagery and the startle-probe reflex. J Abnorm Psychol. 1990; 99(2): 189-197.

82. Witvliet CVO, Vrana SR. Psychophysiological responses as indices of affective dimensions. Psychophysiology. 1995; 32(5): 436-443.

83. Lang PJ, Levin DN, Miller GA, Kozak MJ. Fear behavior, fear imagery, and the psychophysiology of emotion: the problem of affective response integration. J Abnorm Psychol. 1983; 92(3): 276-306.

84. Weerts TC, Lang PJ. Psychophysiology of fear imagery: differences between focal phobia and social performance anxiety. J Consult Clin Psychol. 1978; 46(5): 1157-1159.

85. Cuthbert BN, Lang PJ, Strauss C, Drobes D, Patrick CJ, Bradley MM. The psychophysiology of anxiety disorder: fear memory imagery. Psychophysiology. 2003; 40(3): 407-422.

86. Sabatinelli D, Bradley MM, Lang PJ, Costa VD, Versace F. Pleasure rather than salience activates human nucleus accumbens and medial prefrontal cortex. JNeurophysiol. 2007; 98(3): 1374-1379.

87. Costa VD, Lang PJ, Sabatinelli D, Versace F, Bradley MM. Emotional imagery: assessing pleasure and arousal in the brain's reward circuitry. Hum Brain Mapp. 2010; 31(9): 1446-1457. 
88. Kim S-E, Kim J-W, Kim J-J, et al. The neural mechanism of imagining facial affective expression. Brain Res. 2007; 1145(suppl C): 128-137.

89. Lee S, Ruiz S, Caria A, Veit R, Birbaumer N, Sitaram R. Detection of cerebral reorganization induced by real-time fMRI feedback training of insula activation: a multivariate investigation. Neurorehabil Neural Repair. 2011; 25(3): 259-267.

90. Andrade J, Kavanagh D, Baddeley A. Eye-movements and visual imagery: a working memory approach to the treatment of post-traumatic stress disorder. Br J Clin Psychol. 1997; 36(Pt 2): 209-223.

91. Kavanagh DJ, Freese S, Andrade J, May J. Effects of visuospatial tasks on desensitization to emotive memories. Br J Clin Psychol. 2001; 40(Pt 3): 267-280.

92. Engelhard IM, van den Hout MA, Janssen WC, van der Beek J. Eye movements reduce vividness and emotionality of "flashforwards". Behav Res Ther. 2010; 48(5): 442-447.

93. Engelhard IM, van den Hout MA, Dek ECP, et al. Reducing vividness and emotional intensity of recurrent "flashforwards" by taxing working memory: an analogue study. J Anxiety Disord. 2011; 25(4): 599-603.

94. Lilley SA, Andrade J, Turpin G, Sabin-Farrell R, Holmes EA. Visuospatial working memory interference with recollections of trauma. Br J Clin Psychol. 2009; 48(Pt 3): 309-321.

95. Lau-Zhu A, Holmes EA, Butterfield S, Holmes J. Selective association between tetris game play and visuospatial working memory: a preliminary investigation. Appl Cogn Psychol. 2017 31(4): 438-445.

96. James EL, Lau-Zhu A, Clark IA, Visser RM, Hagenaars MA, Holmes EA. The trauma film paradigm as an experimental psychopathology model of psychological trauma: intrusive memories and beyond. Clin Psychol Rev. 2016; 47: 106-142.

97. Holmes EA, James EL, Coode-Bate T, Deeprose C. Can playing the computer game "Tetris" reduce the build-up of flashbacks for trauma? A proposal from cognitive science. PLoS One. 2009; 4(1): e4153.

98. Iyadurai L, Blackwell SE, Meiser-Stedman R, et al. Preventing intrusive memories after trauma via a brief intervention involving Tetris computer game play in the emergency department: a proof-of-concept randomized controlled trial. $\mathrm{Mol}$ Psychiatry. 2017; (March).

99. Horsch A, Vial Y, Favrod C, et al. Reducing intrusive traumatic memories after emergency caesarean section: A proof-ofprinciple randomized controlled study. Behav Res Ther. 2017; 94: $36-47$.

100. Holmes EA, Lang TJ, Shah DM. Developing interpretation bias modification as a "cognitive vaccine" for depressed mood: imagining positive events makes you feel better than thinking about them verbally. J Abnorm Psychol. 2009; 118(1): 76-88.

101. Holmes EA, Mathews A, Mackintosh B, Dalgleish T. The causal effect of mental imagery on emotion assessed using pictureword cues. Emotion. 2008; 8(3): 395-409.

102. Nelis S, Holmes EA, Palmieri R, Bellelli G, Raes F. Thinking back about a positive event: the impact of processing style on positive affect. Front Psychiatry. 2015; 6: 3.

103. Holmes EA, Coughtrey AE, Connor A. Looking at or through rosetinted glasses? Imagery perspective and positive mood. Emotion. 2008; 8(6): 875-879.

104. Holmes EA, Geddes JR, Colom F, Goodwin GM. Mental imagery as an emotional amplifier: application to bipolar disorder. Behav Res Ther. 2008; 46(12): 1251-1258.

105. Carver CS. Approach, avoidance, and the self-regulation of affect and action. Motiv Emot. 2006; 30(2): 105-110.

106. Lang PJ, Bradley MM. Emotion and the motivational brain. Biol Psychol. 2010; 84(3): 437-450.
107. Kavanagh DJ, Andrade J, May J. Imaginary relish and exquisite torture: the elaborated intrusion theory of desire. Psychol Rev. 2005; 112(2): 446-467.

108. Tiggemann M, Kemps E. The phenomenology of food cravings: the role of mental imagery. Appetite. 2005; 45(3): 305-313.

109. Harvey K, Kemps E, Tiggemann M. The nature of imagery processes underlying food cravings. Br J Health Psychol. 2005; 10(Pt 1): 49-56

110. May J, Andrade J, Kavanagh DJ, Penfound L. Imagery and strength of craving for eating, drinking, and playing sport. Cogn Emotion. 2008; 22(4): 633-650.

111. Maude-Griffin P, Tiffany ST. Production of smoking urges through imagery: the impact of affect and smoking abstinence. Exp Clin Psychopharmacol. 1996; 4(2): 198-208.

112. Tiffany ST, Drobes DJ. Imagery and smoking urges: the manipulation of affective content. Addict Behav. 1990; 15(6): 531-539.

113. Drobes DJ, Tiffany ST. Induction of smoking urge through imaginal and in vivo procedures: physiological and self-report manifestations. J Abnorm Psychol. 1997; 106(1): 15-25.

114. Heishman SJ, Lee DC, Taylor RC, Singleton EG. Prolonged duration of craving, mood, and autonomic responses elicited by cues and imagery in smokers: effects of tobacco deprivation and sex. Exp Clin Psychopharmacol. 2010; 18(3): 245-256.

115. Vanhaudenhuyse A, Bruno M-A, Brédart S, Plenevaux A, Laureys S The challenge of disentangling reportability and phenomenal consciousness in post-comatose states. Behav Brain Sci. 2007; 30(5-6): 529-530.

116. Morewedge CK, Huh YE, Vosgerau J. Thought for food: imagined consumption reduces actual consumption. Science. 2010; 330(6010): 1530-1533.

117. Kilts CD, Schweitzer JB, Quinn CK, et al. Neural activity related to drug craving in cocaine addiction. Arch Gen Psychiatry. 2001; 58(4): 334-341.

118. Tiggemann M, Kemps E, Parnell J. The selective impact of chocolate craving on visuospatial working memory. Appetite. 2010; 55(1): 44-48.

119. Littel M, van den Hout MA, Engelhard IM. Desensitizing addiction: using eye movements to reduce the intensity of substance-related mental imagery and craving. Front Psychiatry. 2016; 7:14.

120. Schumacher S, Kemps E, Tiggemann M. Acceptance- and imagerybased strategies can reduce chocolate cravings: A test of the elaborated-intrusion theory of desire. Appetite. 2017; 113: 63-70.

121. Skorka-Brown J, Andrade J, Whalley B, May J. Playing Tetris decreases drug and other cravings in real world settings. Addict Behav. 2015; 51: 165-170.

122. Andrade J, Pears S, May J, Kavanagh DJ. Use of a clay modeling task to reduce chocolate craving. Appetite. 2012; 58(3): 955-963.

123. Kemps E, Tiggemann M. Hand-held dynamic visual noise reduces naturally occurring food cravings and craving-related consumption. Appetite. 2013; 68: 152-157.

124. May J, Andrade J, Panabokke N, Kavanagh D. Visuospatial tasks suppress craving for cigarettes. Behav Res Ther. 2010; 48(6): 476-485.

125. Hamilton J, Fawson S, May J, Andrade J, Kavanagh DJ. Brief guided imagery and body scanning interventions reduce food cravings. Appetite. 2013; 71: 158-162.

126. May J, Andrade J, Batey H, Berry L-M, Kavanagh DJ. Less food for thought. Impact of attentional instructions on intrusive thoughts about snack foods. Appetite. 2010; 55(2): 279-287.

127. Firmin MW, Gillette AL, Hobbs TE, Wu D. Effects of olfactory sense on chocolate craving. Appetite. 2016; 105: 700-704.

128. Kemps E, Tiggemann M. Competing visual and olfactory imagery tasks suppress craving for coffee. Exp Clin Psychopharmacol. 2009; 17(1): 43-50. 
129. Versland A, Rosenberg H. Effect of brief imagery interventions on craving in college student smokers. Addict Res Theory. 2007; 15(2): 177-187.

130. Kemps E, Tiggemann M. Modality-specific imagery reduces cravings for food: an application of the elaborated intrusion theory of desire to food craving. J Exp Psychol Appl. 2007; 13(2): 95-104.

131. Morina N, Deeprose C, Pusowski C, Schmid M, Holmes EA. Prospective mental imagery in patients with major depressive disorder or anxiety disorders. J Anxiety Disord. 2011; 25(8): 1032-1037.

132. Pile V, Lau JYF. Looking forward to the future: impoverished vividness for positive prospective events characterises low mood in adolescence. J Affect Disord. 2018; 238(April): 269-276.

133. Hirsch CR, Holmes EA. Mental imagery in anxiety disorders. Psychiatry. 2007; 6(4): 161-165.

134. Association AP. Diagnostic and Statistical Manual of Mental Disorders. 5th ed. Arlington, VA: American Psychiatric Publishing; 2013.

135. Ehlers A, Hackmann A, Michael T. Intrusive re-experiencing in post-traumatic stress disorder: phenomenology, theory, and therapy. Memory. 2004; 12(4): 403-415.

136. Grey N, Holmes EA. "Hotspots" in trauma memories in the treatment of post-traumatic stress disorder: a replication. Memory. 2008; 16(7): 788-796.

137. Coughtrey AE, Shafran R, Lee M, Rachman S. The treatment of mental contamination: a case series. Cognit Behav Pract. 2013; 20(2): 221-231.

138. Hirsch CR, Clark DM, Mathews A, Williams R. Self-images play a causal role in social phobia. Behav Res Ther. 2003; 41(8): 909-921.

139. Borkovec TD, Alcaine O, Behar E. Avoidance theory of worry and generalized anxiety disorder. In: Heimberg RG, Turk CL, Mennin DS, eds. Generalized Anxiety Disorder: Advances in Research and Practice. New York: The Guildford Press; 2004.

140. Stöber J. Worry, problem elaboration and suppression of imagery: the role of concreteness. Behav Res Ther. 1998; 36(7-8): 751-756.

141. Behar E, DiMarco ID, Hekler EB, Mohlman J, Staples AM. Current theoretical models of generalized anxiety disorder (GAD): conceptual review and treatment implications. J Anxiety Disord. 2009; 23(8): 1011-1023.

142. Dadds MR, Hawes D, Schaefer B, Vaka K. Individual differences in imagery and reports of aversions. Memory. 2004; 12(4): 462-466.

143. Dadds MR, Bovbjerg DH, Redd WH, Cutmore TRH. Imagery in human classical conditioning. Psychol Bull. 1997; 122(1): 89-103.

144. Holmes EA, Blackwell SE, Burnett Heyes S, Renner F, Raes F. Mental imagery in depression: phenomenology, potential mechanisms, and treatment implications. Annu Rev Clin Psychol. 2016; 12(1): 249-280.

145. Weßlau C, Cloos M, Höfling V, Steil R. Visual mental imagery and symptoms of depression - results from a large-scale webbased study. BMC Psychiatry. 2015; $15(1)$ : 308.

146. MacLeod AK, Conway C. Well-being and positive future thinking for the self versus others. Cogn Emotion. 2007; 21(5): 1114-1124.

147. MacLeod AK, Salaminiou E. Reduced positive future-thinking in depression: cognitive and affective factors. Cogn Emotion. 2001; 15(1): 99-107.

148. MacLeod AK, Tata P, Tyrer P, Schmidt U, Davidson K, Thompson $\mathrm{S}$. Hopelessness and positive and negative future thinking in parasuicide. Br J Clin Psychol. 2005; 44(Pt 4): 495-504.

149. Szőllősi Á, Pajkossy P, Racsmány M. Depressive symptoms are associated with the phenomenal characteristics of imagined positive and negative future events. Appl Cogn Psychol. 2015; 29(5): 762-767.

150. Murphy F, Veers P V, Blackwell SE, Holmes EA, Manly T. Anticipated and imagined futures: prospective cognition and depressed mood following brain injury. 2017
151. Patel T, Brewin CR, Wheatley J, Wells A, Fisher P, Myers S. Intrusive images and memories in major depression. Behav Res Ther. 2007; 45(11): 2573-2580.

152. Renner F, Ji JL, Pictet A, Holmes EA, Blackwell SE. Effects of engaging in repeated mental imagery of future positive events on behavioural activation in individuals with major depressive disorder. Cognit Ther Res. 2017; 41(3): 369-380.

153. Hales SA, Deeprose C, Goodwin GM, Holmes EA. Cognitions in bipolar affective disorder and unipolar depression: imagining suicide. Bipolar Disord. 2011; 13(7-8): 651-661.

154. Ivins A, Di Simplicio M, Close H, Goodwin GM, Holmes E. Mental imagery in bipolar affective disorder versus unipolar depression: investigating cognitions at times of 'positive' mood. J Affect Disord. 2014; 166: 234-242.

155. Gregory JD, Brewin CR, Mansell W, Donaldson C. Intrusive memories and images in bipolar disorder. Behav Res Ther. 2010; 48(7): 698-703.

156. Meyer TD, Finucane L, Jordan G. Is risk for mania associated with increased daydreaming as a form of mental imagery? J Affect Disord. 2011; 135(1-3): 380-383.

157. O'Donnell C, Di Simplicio M, Brown R, Holmes EA, Burnett Heyes $\mathrm{S}$. The role of mental imagery in mood amplification: an investigation across subclinical features of bipolar disorders. Cortex. 2017; 105: 1-14.

158. Hasking PA, Di Simplicio M, McEvoy PM, Rees CS. Emotional cascade theory and non-suicidal self-injury: the importance of imagery and positive affect. Cogn Emot. August 2017: 1-12.

159. McEvoy PM, Hayes S, Hasking PA, Rees CS. Thoughts, images, and appraisals associated with acting and not acting on the urge to self-injure. J Behav Ther Exp Psychiatry. 2017; 57 (suppl C): 163-171.

160. Holmes EA, Crane C, Fennell MJV, Williams JMG. Imagery about suicide in depression-"Flash-forwards"? J Behav Ther Exp Psychiatry. 2007; 38(4): 423-434.

161. Crane C, Shah D, Barnhofer T, Holmes EA. Suicidal imagery in a previously depressed community sample. Clin Psychol Psychother. 2012; 19(1): 57-69.

162. Van Orden KA, Witte TK, Cukrowicz KC, Braithwaite SR, Selby EA, Joiner TE Jr. The interpersonal theory of suicide. Psychol Rev. $2010 ; 117(2)$ : 575-600.

163. Selby EA, Anestis MD, Joiner TE, Selby EA, Anestis MD, Joiner TE. Behavior modification emotion dysregulation in suicidality. 2007: 867-879.

164. Holaday TC, Brausch AM. Suicidal imagery, history of suicidality, and acquired capability in young adults. J Aggress Conflict Peace Res. 2015; 7(3): 127-138.

165. Ng RMK, Di Simplicio M, McManus F, Kennerley H, Holmes EA. 'Flash-forwards' and suicidal ideation: A prospective investigation of mental imagery, entrapment and defeat in a cohort from the Hong Kong Mental Morbidity Survey. Psychiatry Res. 2016 246(suppl C): 453-460.

166. Wetherall K, Cleare S, Eschle S, et al. From ideation to action: differentiating between those who think about suicide and those who attempt suicide in a national study of young adults. $J$ Affect Disord. 2018; 241(June): 475-483.

167. Kavanagh DJ, May J, Andrade J. Tests of the elaborated intrusion theory of craving and desire: features of alcohol craving during treatment for an alcohol disorder. Br J Clin Psychol. 2009; 48(Pt 3): 241-254.

168. Fox HC, Bergquist KL, Hong K-I, Sinha R. Stress-induced and alcohol cue-induced craving in recently abstinent alcohol-dependent individuals. Alcohol Clin Exp Res. 2007; 31(3): 395-403.

169. Tiffany ST. A cognitive model of drug urges and drug-use behavior: role of automatic and nonautomatic processes. Psychol Rev. 1990 97(2): 147-168. 
170. Connor JP, Kavanagh DJ, Andrade J, et al. Alcohol consumption in young adults: the role of multisensory imagery. Addict Behav. 2014; 39(3): 721-724.

171. Coates JM, Gullo MJ, Feeney GFX, et al. The mini alcohol craving experience questionnaire: development and clinical application. Alcohol Clin Exp Res. 2017; 41(1): 156-164.

172. Clark IA, Holmes EA, Woolrich MW, Mackay CE. Intrusive memories to traumatic footage: the neural basis of their encoding and involuntary recall. Psychol Med. 2016; 46(3): 505-518.

173. Holmes EA, Arntz A, Smucker MR. Imagery rescripting in cognitive behaviour therapy: images, treatment techniques and outcomes. J Behav Ther Exp Psychiatry. 2007; 38(4): 297-305.
174. Blackwell SE, Browning M, Mathews A, et al. Positive imagery-based cognitive bias modification as a web-based treatment tool for depressed adults: a randomized controlled trial. Clin Psychol Sci. 2015; 3(1): 91-111.

175. Wilson AC, Schwannauer M, McLaughlin A, Ashworth F, Chan SWY. Vividness of positive mental imagery predicts positive emotional response to visually presented Project Soothe pictures. Br J Psychol. 2017; 109(2): 259

176. Naismith I, Mwale A, Feigenbaum J. Inhibitors and facilitators of compassion-focused imagery in personality disorder. Clin Psychol Psychother. 2018; 25(2): 283-291.

177. Solbrig L, Whalley B, Kavanagh DJ, et al. Functional imagery training versus motivational interviewing for weight loss: a randomised controlled trial of brief individual interventions for overweight and obesity. Int J Obes. 2018. 